\title{
SIMBOLISME DALAM PESTA DALOK SUKU UUD DANUM: Perspektif Hermeneutika Paul Ricoeur
}

\section{Trio Kurniawan}

STKIP Pamane Talino N gabang, Kalbar

\begin{abstract}
A bstract
The feast of Dalok is the highlight of the feast in the series of death-rites performed by Dayak Uud Danum's tribe in Serawai, District of Sintang, West Borneo. It is the biggest feast celebrated by this tribe. There are plenty of Symbols found in the rites, and they are picturing the relationship among the human beings and also between the people and The Supreme Being, Tahala'. These Symbols are tied each other very closely like a knot. The author of this article is using Paul Ricoeur's hermeneutics to reread and reveal the meaning of symbolical knots which are acceptable to the public.
\end{abstract}

Key Words: Betang, Dalok, Hermeneutics, Death, Tahala'

\begin{abstract}
A bstrak
Pesta Dalok adalah puncak dari rangkaian upacara kematian dalam suku Dayak Uud Danum di Serawai, Kab. Sintang, Kalimantan Barat. Pesta Dalok menjadi pesta terbesar yang dilaksanakan oleh suku ini. Ada begitu banyak simbol dalam ritus-ritus di pesta ini dan semuanya menggambarkan relasi antara sesama manusia maupun antar manusia dengan Realitas Tertinggi, Tahala'. Simbol-simbol ini saling berhubungan dengan sangat erat ibarat sebuah simpul. Penulis menggunakan hermeneutika Paul Ricoeur untuk membaca ulang dan membuka makna dari simpul-simpul simbolik yang dapat diterima oleh masyarakat.
\end{abstract}

Kata Kunci: Betang, Dalok, Hermeneutika, Kematian, Tahala'

\section{Pengantar}

Pesta D alok merupakan puncak dari upacara kematian dalam tradisi masyarakat Dayak Uud Danum di Kec. Serawai, Kab. Sintang, Kalbar. ${ }^{1}$ D alok disebut sebagai pesta pertama-tama untuk menunjukkan kemegahan, kompleksitas dan kesakralannya. Suku Dayak Ngaju 
menyebut pesta ini dengan Tiwah. ${ }^{2} \mathrm{Di}$ dalam Pesta Dalok ini, terdapat puluhan upacara kecil yang disusun sedemikian rupa sehingga, jika ditarik garis besarnya, pesta ini tampak "memuncak". D alok juga disebut sebagai Pesta Angkat Tulang karena di dalam pesta ini, tulang belulang leluhur yang sudah belasan hingga puluhan tahun disemayamkan akan diangkat untuk kemudian dimasukkan ke dalam Sandung/Kodiring (semacam rumah kecil yang dikhususkan untuk menyimpan tulang warga kampung yang sudah di--D alok-kan).

Selanjutnya, halyang dirayakan adalah penghantaran arwah orang yang meninggal menuju Betang Abadi. ${ }^{3}$ Artinya, arwah yang meninggal tidak lagi berkesusahan mengembara di dunia karena setelah Pesta D alok ini, arwah akan mempunyai kamar di dalam Betang ${ }^{4}$ A badi tersebut. Pesta Dalok ini juga dilaksanakan selama minimal 3 hari dengan banyak hewan kurban, mulai dari ayam, babi hingga sapi atau kerbau. Pesta ini dirayakan oleh seluruh warga kampung (dalam banyak kasus, bahkan kampung-kampung lain juga ikut serta dalam pesta ini).

Pesta D alok dilaksanakan dengan aturan adat yang sangat keras. Artinya, segala macam persyaratan dan tuntutan adat harus dipenuhi agar doa-doa dan pengharapan tuan pesta dapat tercapai. Ini juga berarti bahwa Pesta Dalok kaya akan simbol-simbol yang digunakan sepanjang acara. Simbol-simbol ini pada dasarnya menggambarkan realitas keseharian manusia Dayak Uud Danum. Lebih jauh lagi, simbol-simbol ini juga menunjukkan cara manusia Dayak Uud Danum berelasi dengan Tahala'.5

1 Suku Dayak Uud Danum memiliki kelompok kekerabatan terdekat yaitu Suku Dayak N gaju di Kalimantan Tengah. Suku Uud Danum yang berada di Kalimantan Barat sebenarnya berasal dari Kalimantan Tengah.

2 L. Dyson dan A sharani, M.,T iwah U pacara Kematian Pada M asyarakat D ayak N gaju di Kalimantan Tengah, Jakarta: Departemen Pendidikan dan Kebudayan Direktorat Jenderal Kebudayaan, 1980.

3 Betang A badi adalah bentuk surga dalam keyakinan masyarakat Dayak Uud Danum. Suku Dayak N gaju menyebut surga sebagai Lewu T atau H abaras Bulau H agu sung Intan D ia Rumpang Tulang. Singkatnya, ada banyak istilah yang bisa digunakan untuk menamai surga dalam bahasa Dayak pada umumnya.

4 Suku ini dulunya hidup dalam komunitas kesukuannya dan tinggal di betang-betang yang dibangun di setiap kampung. Betang, atau biasa juga disebut sebagai Rumah Panjang, merupakan rumah khas orang Dayak yang di dalamnya terdapat puluhan hingga ratusan bilik. Satu bilik biasanya ditempati oleh satu keluarga. Sampai hari ini, masih ada beberapa betang yang berdiri di pemukiman suku Dayak. Namun karena pengaruh modernitas, secara perlahan para penghuni betang mulai keluar dan mendirikan rumah-rumah bergaya modern. Namun, gaya rumah panggung yang tampak dalam arsitektur rumah betang tak pernah ditinggalkan.

5 Tahala'merupakan Realitas Tertinggi dalam kepercayaan masyarakat Dayak Uud Danum. Di kalangan suku Dayak sendiri ada banyak cara untuk menyebut Realitas Tertinggi, yang sering didengar mungkin Jubata. 
Simbol-simbol dalam Pesta Dalok ini kiranya perlu dimaknai secara lebih mendalam karena perannya yang begitu besar dalam menggambarkan identitas diri masyarakat Dayak Uud Danum. Selain itu, interpretasi atas simbol-simbol tradisi ini justru akan semakin memperkaya khazanah pengetahuan manusia tentang Pesta Dalok. Kebenaran-kebenaran yang tersembunyi di dalam pesta ini perlu juga dinikmati dan dihidupi oleh semakin banyak orang agar tata hidup bersama dapat semakin baik.

Hermeneutika Paul Ricouer kiranya dapat menjadi "senjata" dalam membedah simpul-simpul simbolik Pesta $D$ alok. Ricoeur menguak peran simbol-simbol dalam kehidupan manusia lewat bukunya The Symbolism of Evil. Konsep-konsep dasar yang disajikan oleh Ricoeur dalam buku tersebut akan menjadi panduan untuk menelusuri tahap demi tahap Pesta D alok.

\section{Sekilas tentang Suku Dayak Uud Danum}

Suku Dayak Uud Danum (dalam beberapa literatur disebut juga sebagai Ot Danum atau Uut Danum) merupakan suku yang mendiami dua sisi pegunungan Schwaner di Kalimantan Barat dan Kalimantan Tengah. ${ }^{6}$ Kata Uud Danum, secara etimologis, bisa dimengerti sebagai berikut. U ud merupakan kata yang bisa merujuk pada dua pengertian, yaitu bagian hulu dan atau suku. D anum berarti air atau sungai. Dengan demikian, Uud Danum dimengerti sebagai suku yang berdiam di bagian hulu sungai (air).

Suku Dayak Uud Danum berdiam di hutan-hutan sepanjang hulu sungai Melawi dan Serawai, Kab. Sintang, Kalimantan Barat. Suku Uud Danumini mendiami dua kecamatan yang saling berdampingan, yaitu Kecamatan Serawai dan Kecamatan Ambalau. Kec. Serawai dan Kec. A mbalau dipisahkan oleh dua sungai yaitu sungai Melawi dan Serawai. Alloy, dalam buku Mozaik Dayak, ${ }^{7}$ menjelaskan bahwa dari sisi kebudayaan hampir tidak ada perbedaan antara Suku Uud Danum yang berada di Serawai maupun A mbalau. Perbedaan antara keduanya terletak dari segi kebahasaan. Suku Uud Danum berbahasa Cihie di sungai Serawai dan berbahasa Dohoi di hulu sungai Melawi-Ambalau. ${ }^{8}$

Jumlah total masyarakat Uud Danum secara pasti belum bisa diberikan belum ada pendataan resmi terhadap jumlah mereka. Sebagai

6 Sutimbang N gawan, Fonologi Bahasa D ayak U ud D anum [skripsi diterbitkan], Pontianak: Universitas Tanjungpura, 2013.

7 SurjaniAlloy, dkk., M ozaik D ayakK egeragaman Subsuku dan Bahasa Dayak di Kalimantan Barat, Pontianak: Institut Dayakologi, 2008.

8 Pascal Couderc, 1988. "Preliminary Notes on the Ot Danum of the Melawi" dalam Borneo Research Bulletin, Vol. 20, No. 1, April 1988. 
perbandingan, jumlah masyarakat Serawai adalah 21.922 jiwa (BPS Kabupaten Sintang tahun 2010) dengan mayoritas umat beragama Katolik. Berarti masyarakat Uud Danum Serawai sekitar $60 \%$ dari jumlah tersebut.

Masyarakat Dayak Uud Danum pada zaman dahulu hidup dalam kel ompok sebagaimana suku-suku Dayak pada umumnya. Mereka hidup dari hasil sungai dan hutan. Biasanya mereka membuka ladang untuk memenuhi kebutuhan mereka kan beras dan sayur-mayur. Pada lain kesempatan, mereka akan berburu di hutan dan membuat jerat untuk babi hutan atau hewan lainnya. Ada juga dari mereka yang menjala ikan di sungai. Kaum wanita bertugas memasak, mengasuh anak, mengurus rumah tangga hingga menenun. Pekerjaan kasar biasanya dilakukan oleh kaum pria.

\section{Mitos Penciptaan dalam Suku Dayak Uud Danum}

Pesta Dalok adalah sebuah ritus. Ada ragam prosesi dan doa yang terkandung dal am ritus tersebut. Ritus merupakan aktus perayaan sebuah mitos yang diyakini secara turun temurun. Dalam hal ini, pesta Dalok tentu saja merupakan aktus dari mitologi yang hidup dalam kebudayaan masyarakat Dayak Uud Danum.

Proses melacak sumber-sumber tertulis mengenai mitologi (penciptaan dan kematian) dalam masyarakat Dayak Uud Danum, secara khusus yang berada di Kalimantan Barat, merupakan hal yang cukup sulit dilakukan. Catatan-catatan mengenai kisah-kisah penciptaan ini sulit ditemukan karena tradisi menulis tampaknya tidak menjadi kebiasaan dalam masyarakat Dayak Uud Danum sejak dahulu. Banyak kisah mitologis dalam suku ini justru diwariskan secara lisan.

Mitologi mengenai penciptaan dalam suku Dayak Uud Danum masih bisa ditemukan dalam suku Dayak Ngaju di Kalimantan Tengah yang merupakan kerabat dari suku Dayak Uud Danum. Tampaknya, ada cukup banyak kemiripan dalam mitos penciptaan menurut kedua suku ini berdasarkan penuturan dari penduduk Uud Danum sendiri. Oleh karena itu, mitos penciptaan menurut suku Dayak Ngaju yang akan digunakan sebagai pengantar menuju pemahaman mengenai Pesta Dalok.

Dahulu kala, jauh sebelum manusia diciptakan dan diturunkan ke bumi, jauh sebelum alam semesta diciptakan, bertahtalah Sang Maha Pencipta. ${ }^{9}$ Ia adalah Ranying Pohotara Raja Tuntung Matanandau

9 Mitos penciptaan yang dituliskan dalam artikel ini merupakan saduran langsung dari tulisan Andriani S. Kusni yang berjudul "Ranying Hatalla dan A sal Mula Penciptaan Alam 
Kanaruhan Tambing Kabanteran Bulan atau Ranying Hatalla. Ranying Hatalla bertahta di tempat yang disebut Balai Bulau Napatah Intan Balai Intan Napatah Bulau di sebuah dataran tinggi yang disebut Bukit Bulau Kagantung Gandang Kereng Rabia N unjang Hapalangka Langit. Dataran tinggi ini dikelilingi perairan yang disebut Tasik Malambung Bulau Laut Bapantang Hintan.

Ranying Hatalla memiliki banyak pembantu. Mereka diciptakan dari cahaya. Pembantu-pembantu Ranying Hatalla diciptakan jauh sebelum alam semesta dan manusia ada. Mereka adalah roh baik yang bertugas menyejahterakan dan menjaga keselamatan dan kemanan suku. Pembantu-pembantu Ranying Hatalla ini diistimewakan oleh Ranying $\mathrm{H}$ atalla. Beberapa diantara mereka diberi kekuasaan untuk membebaskan dan mengikat.

Suatu waktu, berangkatlah Ranying Hatalla ke puncak Bukit Bulau Kagantung Gandang Kereng Rabia Nunjang Hapalangka Langit yang terletak di Batang Danum Mendeng N gatimbang Langit, Guhung Tenjek Nyampalak Hawon. Dalam perjalanan menuju puncak dataran tinggi itu, Ranying Hatalla melihat satu wujud. Melihat wujud itu persis sama dengan diri-NYA, Ranying Hatalla pun bertanya,

"Wahai kau yang menyerupai wujud-Ku! Siapakah kau?"

Wujud serupa bayangan itu diam saja. Melihat wujud itu diam saja, Ranying Hatalla pun berkata,

“Karena kau tak menjawab-Ku maka kau kuberi nama. Namamu sekarang adalah Jata Balawang Bulau Kanaruhan Bapager Hintan. Kau adalah penguasa alam bawah yang berada di Papan Malambung Bulau yang bertahta di Laut Bapantan Hintan."

Selepas memberi nama, Ranying Hatalla Ialu mengajak Jata Balawang Bulau ke puncak dataran tinggi Bukit Bulau Kagantung Gandang Kereng Rabia Nunjang Hapalangka Langit. Di puncak dataran tinggi itu, disaksikan oleh Jata Balawang Bulau, Ranying Hatalla berfirman,

“Alangkah indahnya jika AKU menjadikan bumi, langit, bulan, bintang, matahari dan segala isinya. AKU akan membuat tiga alam dan isinya melalui delapan kali penciptaan untuk memenuhi keindahan yang $\mathrm{KU}$ inginkan. Ketiga alam itu adalah alam atas, bumi dan isinya serta alam bawah. A pakah kau setuju, wahai Jata Balawang Bulau?"

Jata Balawang Bulau mengangguk.

Ranying Hatalla lalu melepaskan Sarumpah Bulau di suatu tempat. Seketika terdengar petir menggelegar. Kilat sambar-menyambar.

Semesta" yang bisa dibaca di https://archive.kaskus.co.id/thread/1556234/3. Beberapa bagian dari tul isan A ndriani S. Kusni ini dipotong, namun mayoritas tulisannyatetap dipertahankan. 
Sarumpah Bulau Ialu menjelma menjadi naga. Ciptaan pertama Ranying $\mathrm{H}$ atalla telah terbentuk.Setelah itu Ranying $\mathrm{H}$ atalla melepaskan Lawung Singkap Antang. Membuka dan meletakkannya di atas badan Naga. Seketika terdengar lagi bunyi gemuruh. Petir menggel egar dan kilat sambar-menyambar. Lawung Singkap A ntang tiba-tiba menjelma menjadi Petak Sintel Habalambang Tambun, Liang Deret Habangkalan Karangan. Ini adalah tanah bumi lengkap dengan laut, sungai, danau dan segala isinya juga tumbuh-tumbuhan yang hidup di tanah. Ciptaan kedua Ranying Hatalla terbentuk.

Untuk membuat ciptaan ketiga hingga kedelapan, Ranying Hatalla memutuskan untuk mengambil sifat-sifat baik dan mulia yang dimilikiNYA sebagai bahan dasar ciptaan-NYA. Ranying Hatalla menciptakan naga, bumi dan isinya, batang garing, kekuasaan, enggang betina, elang dan enggang jantan. Namun belum ada Iangit, bulan, bintang dan matahari. Juga belum ada gelap dan terang. Maka, disertai gemuruh halilintar yang sambar-menyambar, diciptakanlah langit, bulan, bintang dan matahari. Langit dibuat tujuh tingkat. Masing-masing tingkat memiliki penjaga. Ditentukan oleh Ranying Hatalla bahwa langit ketujuh adalah puncak langit. Tidak ada langit yang lebih tinggi daripada langit ketujuh. Dilangit ketujuh inilah Ranying $\mathrm{H}$ atalla bertahta dengan segala kuasa-NYA.

Setelah langit selesai diciptakan, Ranying Hatalla menginginkan hiasan yang indah bagi langit. Selain indah, Ranying Hatalla ingin agar hiasan langit itu juga berguna bagi manusia nanti. Maka Ranying $\mathrm{H}$ atalla menciptakan bintang. Bintang-bintang ini akan membantu manusia saat bekerja di ladang dan saat manusia melakukan perjalanan dengan menjadi penunjuk arah.Lalu Ranying Hatalla menentukan gelap dan terang. Maka diciptakanlah matahari dan bulan.Terang disebut siang saat matahari muncul. Gelap adalah malam saat bulan nampak. Alam semesta telah lengkap. Setelah semua sel esai diciptakan, Ranying Hatalla berkata pada segala ciptaan-NYA,

Sekarang Ranying Hatalla ingin melengkapi ketujuh penciptaanNYA dengan penciptaan kedelapan. Ranying Hatalla ingin menciptakan manusia, penghuni alam semesta. Namun sebelum menciptakan manusia, Ranying Hatalla ingin menciptakan tujuh raja yang akan menjadi sahabat dan membantu-NYA membawa ajaran Ranying Hatalla kepada manusia.

Maka, Ranying Hatalla mengambil dua sifat lagi dari diri-NYA. Kedua sifat itu adalah Kemuliaan-NYA yang Maha Suci dan KeagunganNYA yang Maha Mulia. Ranying Hatalla lalu menyatukan kedua sifat tersebut hingga terbentuklah Bukit Intan dan Bukit Emas. Masing-masing bukit memiliki cahaya terang yang berpendar lembut dan hangat. A kibat benturan cahaya Bukit Intan yang menyatu dengan sinar Bukit Emas 
maka lahirlah tujuh raja yang diinginkan Ranying Hatalla. Ketujuh raja ini masing-masing diberi nama. Mereka adalah Raja Mandurut Untung, Raja Mandurut Bulau, Raja Barakat, Raja Angking Penyang, Raja Garing hatungku, Raja Panimbang Darah, dan Raja Tamanang.Setelah ketujuh raja diciptakan, Ranying Hatalla lalu menyatukan Bukit Intan dan Bukit Emas. Penyatuan kedua bukit ini kelak akan menjadi cikal bakal diciptakannya manusia.

Mitos penciptaan ini memiliki beberapa implikasi bagi kepercayaan dan tradisi masyarakat Dayak Ngaju. Salah satunya adalah pada ritus Upacara Tiwah. Sebagaimana Dalok, dalam upacara ini, arwah diantarkan menuju surga yang terletak di langit ke tujuh.

\section{Pesta Dalok: Mengantar Arwah ke Betang A badi}

Pesta Dalokdibagi menjadi dua tingkatan yaitu DalokN ahpeng dan DalokKodiring. Dalok $\mathrm{N}$ ahpeng adalah Dalokyang tidak dibuat Kodiring (rumah tulang) dan tulang tidak diangkat dari kuburnya. Tetapi hanya kuku atau rambut saja yang di pahat pada Sopundu'10. Jika hal ini dilakukan, maka diyakini sang arwah di alam baka hanya mempunyai sebuah Takun (kamar) di dalam rumah (betang) yang permanen. $D$ alokKodiringmaksudnya adalah upacara adat $D$ alokdengan membuat Kodiring (rumah tulang). Jika hal itu dilakukan maka bagi arwah orang yang di-D alok-kan di alam baka akan mempunyai sebuah Lovu (rumah yang sangat permanen). Pada Pesta D alokini, jika penyelenggaraannya membunuh kerbau, maka selain Torasch ${ }^{11}$ dan Sopondu', juga harus mendirikan Sokalan (semacam tiang dari kayu belian besar dan tinggi, pada puncaknya ditempatkan sebuah tempayan).

Pesta D al okdibuka dengan upacara N ohkak U cak (menumbuk padi). Upacara ini dilakukan pertama-tama untuk memberitahu Tahala' bahwa tuan rumah akan mengadakan pesta mengantarkan arwah keluarganya yang telah meninggal sehingga Tahala' berkenan mengijinkan dan memberkati pesta ini.

Dalam PestaD alok ini, Sopundu' termasuk benda sentral. Sopundu' tidak langsung dipasang/ ditancap di halaman rumah. A da upacara awal yang dilaksanakan untuk memasang Sopundu'. U pacara ini disebut $\mathrm{N}$ gitot Sopundu' (mengantar Sopundu'). Setelah upacara ini selesai, barulah Sopundu' bisa didirikan. Pada jaman dahulu, tuan rumah akan meletakkan kepala manusia di bawah Sopundu' untuk menjadi kurban/ tumbal bagi

10 Sopundu'adalah sebuah patung manusia yang terbuat dari kayu Tebelian (Ulin/ kayu besi).

11 Toraschadalah tiang kayu panjang yang ujungnya seperti mata tombak. Kayu ini terbuat dari kayu Tebelian. 
Sopundu' tersebut. Kepala manusia ini diperoleh dari mengayau. Namun kebiasaan ini telah dihentikan sejak disepakatinya perjanjian Tumbang Anoi ${ }^{12}$ di bumi Kalimantan. Pada tiang Sopundu' ini biasanya digantung kepala hewan kurban. Kepala ini dimaksudkan sebagai ucapan syukur kepada Tahala'.

Orang Uud Danum percaya bahwa roh Sopundu' inilah yang akan menjadi budak bagi arwah yang dihantarkan itu. Budaknya ini akan melayani arwah yang dihantarkan itu saat telah berada di Betang abadi. Budaknya inilah yang akan mencuci pakaian, memasak, berburu, ataupun mencari kayu bakar untuk tuannya. Segala macam peralatan yang akan dipakai oleh budak ini nanti dipersiapkan dalam upacara Puhkung ${ }^{13}$.

Upacara terakhir yang sangat penting adalah mengantarkan tulang ke Kodiring/ Sandung. Kodiring adalah sebuah rumah kecil berbentuk betang. Rumah ini berfungsi untuk menampung tulang-belulang sanak keluarga yang telah menjalani Pesta Dalok. Kodiring ini adalah miniatur surga bagi arwah yang telah meninggal. Pada jaman dahulu, ada kebiasaan untuk mengabukan tulang-tulang tersebut sehingga yang dibawa masuk ke Kodiring adalah abu dalam guci kecil. Pengabuan ini dimaksudkan sebagai penghapusan dosa dan salah dari arwah yang telah meninggal. Namun kebiasaan ini telah lama ditinggalkan.

Tulang belulang orang yang dipestakan ini dibawa oleh suami, istri ataupun anak-anaknya. Untuk membawa tulang ini, ia harus mengenakan Takui Dalok, mandau dan kain penggendong. Tulang belulang ini diletakkan di dalam kain tersebut. Upacara pengantaran terakhir ini disebut $\mathrm{N}$ aloh. Dengan dihantarkannya tulang-belulang ini ke Kodiring, masyarakat Uud Danum meyakini bahwa arwah yang dihantarkan telah sampai ke Betang abadinya. Untuk mengusir segenap roh jahat ataupun 0 tu' (hantu) yang mengikuti masyarakat selama Pesta Dalok, diadakanlah Hopohau'14.

Dari seluruh rangkaian Pesta Dalokini, ada dua hal besar yang diyakini oleh masyarakat Uud Danum berkaitan dengan ketuhanan dan kemanusiaan, yaitu:

1. Masyarakat Uud Danum mempercayai adanya Dia Yang Tinggi, yang mereka sebut sebagai Tahala'15. Tahala' ini adalah pribadi yang

12 Pertemuan pada tanggal 1Januari 1894 di Tumbang A noi ini membahas tentang kesepakatan untuk berhenti mengayau dan membebaskan para jihpon (budak)

13 Semacam tarian roh yang dilakukan pada malam saat tulang masi h berada di pondok dekat rumah tuan pesta.

14 H opohau'yaitu semacam permainan masyarakat yang mengikuti Pesta Dalok. Orang-orang yang mengikuti Pesta Dalok saling melempar ataupun melumuri badan dengan oli bekas, minyak rambut, lumpur, minyak goreng bekas, dan bahkan kotoran babi dan sapi.

15 Bisa dilihat pada upacara pendirian Sopundu'. Masyarakat mel etakkan kepala kerbau sebagai ucapan syukur pada Tahala' (atau masih banyak contoh lainnya). 
transenden, tak tertandingi. Tahala'inilah yang mengatur hidup atau mati, kesuburan atau kegagalan panen. Karena itu, arwah orang yang telah mati akan dihantarkan kembali kepada Tahala'sehingga Tahala'akan menjaga lagi arwah orang tersebut di dalam kehidupan yang baru.

2. Masyarakat Uud Danum percaya bahwa ada kehidupan lagi setelah kematian. ${ }^{16}$ Pertanyaan mendasar yang muncul di benak mereka adalah: kemana arwah manusia pergi setelah ia mengalami kematian? Hilangkah jiwa dan raganya? Pertanyaan ini terjawab ketika mereka mengalami mimpi. Dalam mimpi tersebut, mereka berjumpa dengan arwah sanak keluarga yang telah mati. Karena itu, mereka kemudian meyakini bahwa ada kehidupan setelah kematian. Masyarakat Dayak Uud Danum percaya bahwa mereka (arwah-arwah) tetap memiliki jiwa dan raga yang utuh karena pada saat bermimpi mereka menjumpai arwah tersebut dalam bentuk utuh. Dengan kata Iain, manusia dalam pandangan suku Dayak Uud Danum bersifat immortal (abadi) baik jiwa dan raganya. Karena itulah orang-orang yang telah mati ini tetap diberi makan (pacuh ${ }^{17}$ ) oleh anggota keluarga yang masih hidup.

Cara manusia Uud Danum melihat persoalan kehidupan dan kematian itu unik. Bagi mereka, ada realitas baru dan berkelanjutan sesudah kematian. Manusia yang telah mati tidak akan kehilangan identitasnyajika ia mati. Karena itu, kehidupan di dunia yang selanjutnya ini perlu dipersiapkan. Namun demikian, mereka belum dapat menjelaskan keabadian tubuh fisik secara logis selain hanya bersum berdari "penglihatan" dalam mimpi.

\section{Fungsi-Fungsi Simbolis dari Mitos: Analisis Hermeneutika dari buku The Symbolism of Evil karya Paul Ricoeur}

Paul Ricoeur (1913-2005) merupakan seorang filosof asal Perancis yang karya-karyanya telah diterjemahkan dalam banyak bahasa. Ia telah menulis banyak buku dan lebih dari 500 esai selama hidupnya. Karyakaryanya ini banyak terfokus pada persoalan filsafat-antropologi, walau ia akhirnya dikenal luas sebagai seorang pakar hermeneutika. Selain itu, Ricoeur juga merupakan seorang analisis sosial dan ruang publik di Perancis.

16 Ada banyak contoh dalam upacara ini, mis.: makna pada patung sopundu', persiapan lovu', penempatan tulang pada kodiring, dll.

17 Upacara kecil untuk memberi makan arwah orang yang sudah meninggal. U pacara ini biasa dilakukan pada saat anggota keluarga yang masih hidup melaksanakan pesta. Caranya yaitu dengan melemparkan makanan (ayam, nasi dlI) keluar rumah menggunakan tangan kiri. 
Salah satu karya Paul Ricoeur adalah The Symbolism of Evil. ${ }^{18}$ Buku ini merupakan tanda pergeseran pemikiran Paul Ricoeur dari telaah fenomenologi kepada hermeneutika simbol. Ricoeur tampaknya menyadari bahwa dalam relasi antar manusia, tanda tidak lagi menjadi sekadar hal yang muncul sebagai kepentingan intuitif antar manusia. Lebih jauh lagi, relasi antar manusia pada dasarnya selalu dimediasi oleh tanda atau simbol. Mengungkap selubung tanda/ simbol berarti membuka relasi antar manusia itu sendiri.

Persoalannya, mengapa Ricoeur mengambil tema kejahatan? Ia tampaknya gelisah dengan fenomena kejahatan yang selalu ada dalam diri setiap manusia dan realitas sosial nya. Ketika berhadapan dengan kejahatan, manusia diajak untuk melihat kembali kualitas kesadaran diri dan kehendaknya. A rtinya, kejahatan selalu berada dal am dua komponen tersebut. Kejahatan merupakan bentuk perlawanan atas kesadaran diri dan kehendak manusia yang selalu mengejar kebaikan. Kejahatan hadir seperti mimpi buruk yang menghantui keseharian manusia. Kegelisahan ini menghadirkan pertanyaan besar di dalam dirinya: darimana kejahatan berasal? Pertanyaan ini menuntunnya pada refleksi besar tentang simbolsimbol kejahatan yang muncul dalam kisah-kisah penciptaan dunia. Simbol-simbol dalam mitos maupun kebudayaan merupakan bentuk rasionalitas kesadaran diri manusia. Sebagaimana yang diketahui pada umumnya, ketika manusia masih belum mengenal modernitas, mitologi dan tradisi menjadi jembatan bagi manusia untuk memahami realitas dunia yang sedemikian kompleks, termasuk di dalamnya realitas kejahatan.

\subsection{Fungsi Simbolis dari Mitos-Mitos}

Paul Ricoeur mengatakan bahwa apa yang manusia rasakan sebagai rasa bersalah, rasa berdosa, rasa tercemar mensyaratkan suatu perantara (media/ sarana) agar dapat dipahami. Ricoeur menyebut perantara tersebut sebagai bahasa simbolik. ${ }^{19}$ Tanpa adanya bahasa simbol, pengalaman akan menjadi bisu dan tak berarti apa-apa di tengah segala macam kontradiksi yang ada di dalamnya. Pernyataan Ricoeur ini menjadi sangat penting karena konsepnya tentang mitos dibangun di atas dasar bahasa simbolik.

Manusia modern saat ini kehilangan cara untuk memahami mitos karena proses demitologisasi yang terjadi selama berabad-abad, terutama

18 Sebagian besar analisis dalam artikel ini diambil dari buku tersebut. - Paul Ricoeur, The Symbolism of Evil, London: Beacon Press, 1967.

19 "[...] what is experienced as defilement, as sin, as guilt, requires the mediation of a specific language, the language of symbols. W ithout the hel p of thelanguage, the experiencew ould remain mute, obscure and shut up in its implicit contradictions [...]" - Bdk. Ibid., 161. 
sejak filsafat mulai menancapkan klaim-klaim ilmu pengetahuannya. Demitologisasi merupakan proses yang dimulai oleh para filosof Yunani klasik (Thales, Anaximandros dan sebagainya) dengan tujuan untuk memahami realitas tanpa diberi "embel-embel" dongeng/ mitos yang seringkali terlihat irrasional. Proses ini pada akhirnya memakan "korban" yang sangat banyak, yaitu kegagalan manusia modern dalam memahami lagi mitos-mitos lampau. M itos-mitos ini, jika dibaca lagi, tampaknya telah kehilangan konteks antropologis, geografis, semantik dan lain sebagainya.

Paul Ricoeur mengatakan bahwa untuk memahami mitos sebagai mitos, manusia harus mampu memahami pengertian mitos itu sendiri, bagaimana konteks waktunya, bagaimana diceritakan, peristiwa yang muncul apa saja dan masi h banyak lagi. Memahami mitos hanya sebagai dongeng biasa akan membuat mitos tersebut kehilangan makna dan rasionalitasnya. Dengan kata lain, manusia tidak boleh menyederhanakan mitos sebagai kisah pengantar tidur semata jika benar-benar ingin mengerti mitos tersebut.

Paul Ricoeur merumuskan setidaknya ada 3 fungsi simbolis dari mitos-mitos (terutama mitos tentang kejahatan): ${ }^{20}$

1. Fungsi pertama mitos tentang kejahatan adalah untuk merangkum kemanusiaan secara menyeluruh ke dalam satu sejarah yang ideal. Sebagai contoh, ketika Kitab Suci menggunakan Adam sebagai manusia pertama dalam mitos penciptaan, Adam di sini sebenarnya menggambarkan seluruh kemanusiaan umat manusia. Dengan begitu, keberdosaan Adam dalam kisah di Taman Eden menunjukkan keberdosaan umat manusia pada umumnya. Jiwa A dam begitu rentan terhadap godaan kejahatan, persis seperti apa yang terjadi dengan manusia hari ini.

2. Universalitas manusia dimanifestasikan lewat mitos dan mendapatkan karakter konkritnya lewat narasi yang disajikan dalam mitos tersebut. Dalam narasi yang dibangun lewat mitos, awal mula kejahatan hingga berakhirnya dikisahkan dalam satu cerita utuh. A rtinya, momen "saat ini" yang diceritakan lewat mitos pada dasarnya merupakan momen keseluruhan hidup manusia dari awal hingga akhir. Ada proses jatuh dan bangun, proses keberdosaan dan penyel amatan, semuanya terangkum dalam mitos. Dengan kata lain, mitos adalah narasi yang memperlihatkan sejarah esensial manusia, yaitu kebinasaan dan keselamatan.

3. Mitos juga mencoba memberikan teka-teki tentang eksistensi manusia, misalnya perbedaan mendasar tentang situasi awal manusia (fundamental reality) yang tampaknya tanpa dosa, suci dan

20 Ibid., 162. 
utuh di hadapan Tuhan dengan situasi aktualnya yang penuh dosa dan rasa bersalah. Ada persoalan besar di sini: mengapa secara fundamental manusia itu tanpa noda namun pada tataran riilnya ia begitu berdosa? Mitos menyajikan transisi antara situasi fundamental kepada situasi aktual ini dalam narasi-narasi yang begitu indah; antara hakekat sejati diri manusia dan eksistensi historisnya dalam dunia aktual.

Dengan mitos, dunia menjadi seakan-akan dunia yang penuh keberdosaan, penuh kesalahan. Itu karena orientasi yang selalu ditawarkan dalam mitos merupakan situasi kejatuhan manusia, entah dalam mitos apapun itu. Tak ada mitos (penciptaan khususnya) yang tidak menyajikan kisah tentang kejatuhan dan keberdosaan. Bahkan dalam mitos-mitos keseharian pun tema kejatuhan (Ialu kemudian diselamatkan) ini menjadi semacam pola tetap.

Banyak orang dengan begitu saja menyamakan antara mitos dan alegori. A da perbedaan mendasar antara kedua hal ini. Menurut Ricoeur, sebuah alegori dapat dengan begitu saja diterjemahkan ke dalam teks yang bisa dipahami dengan sendirinya. Sekali saja sebuah alegori diterjemahkan, langsung pada saat itu ia kehilangan karakternya. Berbeda dengan itu, mitos memiliki caranya sendiri dalam merevelasikan kebenaran. Cara ini tidak bisa direduksi ke dalam terjemahan apapun. Mitologi berkarakter otonom dan apa adanya. ${ }^{21}$

\subsection{D rama Penciptaan dalam Teks Enuma Elish}

Banyak teks tentang penciptaan dunia menunjukkan dengan sangat jelas situasi asali semesta raya ini yang tak beraturan (chaos). Paul Ricoeur menyebutnya sebagai primordial chaos. Situasi tak beraturan dari semesta ini kemudian, oleh kuasa Yang Absolut, diubah menjadi tatanan yang begitu indah dan rapi (cosmos). Perubahan dari kekacauan menuju tatanan yang indah ini mengandaikan satu hal penting, bahwa dunia sejak semula digambarkan sebagai suatu keadaan yang kacau, penuh kejahatan dan tanpa arah.

Salah satu teks klasik yang menggambarkan dengan jelas situasi asali ini dalam narasinya adalah Enuma Elish. Enuma Elish merupakan salah satu mitos penciptaan yang berasal dari bangsa Babilonia. Teks ini terdiri atas lebih dari 1000 baris syair yang dikelompokkan dalam 7 lempengan tanah liat. Masing-masing lempengan terdiri atas 115-170 baris syair. Teks ini diperkirakan ditulis pada tahun 1100 SM.

Untuk memahami mitos penciptaan ini, baik kiranya jika tokohtokohnya diperkenalkan terlebih dahulu. Ada 2 Dewa Purba yang

21 Ibid., 163-164. 
diyakini ada menurut teks ini, yaitu Dewa Apsu (Dewa Air Tawar) dan Dewa Tiamat (Dewa Air Laut). Selain itu, ada Dewa-Dewa lainnya yang dilahirkan dari Dewa Tiamat ataupun Dewa A psu, salah satunya adalah Dewa Ea. Selain itu, ada Dewa Mummu yang merupakan anak dari Dewa A psu dan Damkina (istri Dewa Ea). Terakhir, ada Marduk sebagai tokoh sentral mitos Enima Elish. Marduk merupakan anak dari Dewa Ea dan Damkina.

Narasi mitos dalam E numa Elish dimulai sebagai berikut: ${ }^{22}$ ada 2 dewa purba yaitu Apsu dan Tiamat. Tiamat adalah dewa yang sangat besar. Dari perkawinannya dengan Kingu lahirlah dewa-dewa lain seperti Dewa Ea.Dewa Ea dan dewa-dewa lainnya ternyata memunculkan kebisingan sehingga Dewa Apsu marah. Dewa Apsu kemudian, setelah berdiskusi dengan Mummu, memutuskan untuk membunuh Dewa Ea dan saudarasaudaranya. Tiamat tidak setuju.

Tiamat Ialu membocorkan niat buruk Apsu ini kepada Ea. Dengan sihirnya, Ea membuat A psu tertidur koma dan kemudian membunuhnya. Ea memiliki istri yang bernama Damkina dan anak yang bernama Marduk. Marduk memiliki kekuatan angin sehingga kekuatan ini sering menganggu dewa-dewa yang lain. A nak-anak Apsu (dewa yang lainnya) menuntut balas kematian ayahnya dan meminta pertolongan Tiamat untuk membunuh Ea, Damkina dan Marduk. Tiamat kemudian menciptakan 11 monster yang sangat mengerikan. Monster-monster ini kemudian justru menjadi ancaman bagi dewa-dewa lainnya.

Marduk mengajukan syarat: jika ingin selamat, angkat dirinya menjadi pemimpin untuk mengalahkan Tiamat. Dewa-dewa setuju. Marduk berduel melawan Tiamat. Tiamat kalah dan dicabik menjadi dua, satu menjadi langit dan satunya menjadi bumi. Marduk kemudian menciptakan kalender, mengatur tata surya dan lain sebagainya. Ia membunuh Kingu dan dari darahnya diciptakan manusia yang harus mengabdi pada para dewa.

\subsection{Rasionalitas Manusia dalam Mitos}

Dalam Enuma Elish, Paul Ricoeur menemukan bahwa keadaan asali dunia adalah kacau (chaos). Menurutnya, asal mula segala sesuatu pada dasarnya diwakili oleh sosok Marduk yang melambangkan dua sisi yaitu kebaikan dan kejahatan. Sisi kejahatan tampak dalam penghancuran, pembunuhan dan pemusnahan yang dilakukan oleh Marduk. Sisi kebaikan tampak dalam usaha Marduk untuk membangun tatanan baru (cosmos). Jadi, Ricoeur menyimpulkan bahwa ada perubahan situasi dari

22 Bentuk agak panjang dari kisah dalam mitos Enuma Elish ini ditulis oleh Paul Ricoeur dalam buku The Symbolism of Evil mulai dari halaman 175-190. - I bid., 175-190. 
yang buruk menuju ke yang baik. Kejahatan dihancurkan dan muncullah kebaikan (tatanan baru) yang adalah Dewa (Kerajaan Tuhan). Hanya melalui Perang dan Pembunuhan barulah kekacauan (chaos) dapat diatasi.

Paul Ricoeur dalam kesimpulan akhirnya mengatakan bahwa teks Enuma Elish ini menunjukkan gambaran kodrati manusia yang di dalam dirinya ternyata menyimpan kejahatan. ${ }^{23}$ Manusia sering bertanya mengapa setiap orang selalu terdapat kecenderungan untuk menjadi jahat. Teks Enuma Elish ini menunjukkan peran sentral para dewa yang membuat dunia sejak awal sudah kacau dan penuh kejahatan. A palagi kisah darah Kingu yang kemudian menjadi asal muasal manusia semakin menegaskan bahwa di dalam hidup manusia unsur chaos dan kejahatan merupakan bagian yang tak terpisahkan dari diri mereka.

Bagi Paul Ricoeur, para tokoh dan kisah dalam Enuma Elish merupakan simbol-simbol yang digunakan oleh bangsa Babilonia untuk menjelaskan realitas manusia hari ini. Mitos selalu memiliki makna ontologis. Dengan mengisahkan keadaan asali manusia, mitos justru menunjukkan situasi historis manusia hari ini. Mitos merangsang manusia kemampuan manusia untuk berpikir dan memahami realitas.

Realitas manusia merupakan semesta yang sangat luas dan seringkal $i$ tak terpahami. Ada begitu banyak misteri yang menunggu akal budi manusia untuk menyelaminya. Mitos, sekali lagi, adalah salah satu sarana manusia untuk membahasakan realitas manusia yang gelap tersebut. Dengan mempelajari mitos, filsafat membongkar sisi gelap/ terlupakan dari eksistensi manusia. Filsafat hadir untuk menyelami labirin-labirin realitas manusia.

\section{Pesta Dalok dalam Pusaran Rasionalitas Manusia Dayak U ud Danum: Kesejajaran antara Mitos dan Tradisi}

Secara pola dan isi, antara mitos dan tradisi memiliki perbedaan yang cukup signifikan. Mitos berada dalam tataran narasi sementara tradisi berada dalam tataran ritus. Sebagaimana yang sudah disampaikan di atas, narasi mengandaikan adanya tokoh, peran, plot hingga dinamika kisah. Sebaliknya, tradisi tidak mengandaikan hal-hal tersebut. Tradisi bergerak dalam ruang ritus, pembagian tugas antar pelaku tradisi, aturanaturan yang kaku dan lain sebagainya. Teks Enuma Elish merupakan sebuah mitos, sedangkan Pesta D alok merupakan sebuah tradisi.

Pertanyaan penting berkaitan dengan perbedaan antara mitos dan tradisi adalah: bagaimana kedua hal ini bisa disejajarkan? A pakah ada

23 Ibid., 191. 
hal-hal mendasar yang bisa menjembatani keduanya sehingga darinya bisa dijalin sebuah dialog? Ada. Pertama, mitos dan tradisi pertama-tama merupakan kritalisasi dari rasionalitas manusia. Mitos hadir karena rasionalitas manusia tidak mau tunduk pada kebenaran-kebenaran faktual realitas yang disimplifikasikan. ${ }^{24}$ Artinya, ketika berhadapan dengan realitas yang sangat kompleks ini, manusia awal bertanya dari mana segala yang ada ini berasal. Pertanyaan inilah yang kemudian menghadirkan mitologi.

Sama halnya dengan mitos, tradisi juga merupakan buah dari rasionalitas manusia. Kompleksitas relasi antar Yang Maha Tinggi dengan manusia dan antar sesama manusia kemudian dibahasakan lewat tradisi, lewat ritus-ritus yang disepakati dan disakralkan. Segala macam simbol, persyaratan adat hingga pemimpin ritual adat-tradisi pada dasarnya menunjukkan bentuk konkret dari makna relasi tersebut.

Kedua, mitos dan tradisi juga sama-sama mengandaikan bahasa sebagai jembatan untuk menghubungkan apa yang spiritual/ rohani dengan apa yang konkret. Bahasa dalam konteks ini tidak bisa direduksi pada persoalan verbal manusia, misal nya bahasa Indonesia, Inggris, Spanyol, Jawa, Dayak Uud Danum dan Iain sebagainya. Bahasa dimengerti sebagai apa saja yang bisa menunjukkan atau mengkomunikasikan sesuatu hal. Artinya, bahasa memiliki hubungan yang sejajar dengan simbol.

Ketiga, mitos dan tradisi sama-sama mengandaikan sebuah narasi besar yang mampu merangkum universalitas manusia ke dalam satu kisah. Pada mitos, narasi ini dibangun lewat cerita dan penokohan. Tradisi tentu saja ridak menggunakan bentuk yang sama. Tradisi membangun narasinya lewat urut-urutan upacara, pemimpin adat dan masyarakat sebagai anggotanya. Dalam narasi besar ini, mitos dan tradisi bergerak memuncak dan mengarah pada kesempurnaan.

\section{Mengurai Simpul-Simpul Simbolik dalam Pesta Dalok}

Pesta D alok, sebagaimana yang sudah dijelaskan di atas, merupakan puncak dari seluruh rangkaian upacara kematian dalam masyarakat

24 Joseph Raz membahas tema mitos dan rasionalitas manusia ini dalam uraian yang cukup menarik. Ia pertama-tama membedakan antara rasio instrumental (instrumental reason) dan rasional itas instrumental (instrumental rationality). Rasio instrumental merupakan akal budi yang berusaha memahami real itas dan kemudian memaknainya. Sementara itu, rasional itas instrumental merupakan rasio instrumental yang sudah memiliki wajah riil (kristal). Rasio instrumental masih bersifat konseptual dan rasionalitas instrumental sudah berwujud faktual. Mitos, menurut Raz, berada dalam tataran rasional itas instrumental. - Joseph Raz, "The Myth of Instrumental Rationality" dalam J ournal of Ethics and Social Philosophy, Vol I, No. I, April 2005. 
Dayak Uud Danum. Sebagai bentuk rasionalitas dari masyarakat Uud Danum, Pesta Dalok secara jelas merangkum perkara kemanusiaan masyarakat Uud Danum ke dalam satu pesta besar. Perkara kemanusiaan ini ditunjukkan lewat terminologi yang digunakan dalam upacara hingga sampai pada peralatan upacara yang digunakan.

Betang, lovu, babi dan Iain sebagainya merupakan terminologi yang sangat dekat dengan keseharian masyarakat Dayak Uud Danum. Bendabenda ini digunakan untuk menyokong kehidupan mereka. Dengan memasukkan benda-benda ini ke dalam ritus Pesta Dalok, masyarakat Uud Danum sebenarnya merayakan kehidupan mereka sendiri. Mereka menjadikan pesta kematian sebagai proses menuju kehidupan baru dimana betang, lovu, babi dan lain sebagainya tetap menjadi bagian dari keseharian mereka setelah meninggal.

Pesta Dalok juga merangkum persoalan mendasar manusia, yaitu kehidupan dan kematian, ke dalam satu narasi besar. Paul Ricoeur menggunakan Enuma Elish sebagai contoh dari salah satu narasi besar yang menggambarkan persoalan dasar manusia (kebaikan dan kejahatan). Masyarakat Uud Danum menyadari bahwa persoalan kematian selalu ditempatkan dalam hubungannya dengan kehidupan. Kematian tidak lagi menjadi momen yang mengerikan karena mati hanyalah "batu Ioncatan" menuju Betang Abadi dimana Tahala' berkuasa.

Situasi orang mati yang digambarkan dalam Pesta Dalok tidak ada bedanya dengan situasi orang hidup. Itulah sebabnya segala macam keperluan mendasar yang dipersiapkan oleh keluarga orang yang meninggal bagi arwah yang di-D alok-kan juga pertama-tama agar arwah tersebut dapat "hidup" nyaman di Betang Abadi. Mereka harus mempersiapkan kamar, budak hingga makanan dan minuman bagi arwah tersebut.

Selain itu, Pesta Dalok merupakan bentuk rasionalitas masyarakat Dayak Uud Danum berkaitan dengan relasi mereka dengan Yang Maha Tinggi dan relasi mereka dengan sesama. Segala macam hewan kurban yang dikurbankan dalam Pesta Dalok, termasuk semua rumusan doa dalam pesta tersebut, merupakan kristalisasi hubungan antara manusia Dayak Uud Danum dengan Yang Maha Tinggi. Terselenggaranya kehidupan dan kematian merupakan karya utama dari Yang Maha Tinggi. Itulah sebabnya masyarakat Dayak Uud Danum merasa bahwa wajib untuk selalu berkontak dengan Tahala' dalam setiap upacara kehidupan mereka, termasuklah di dalamnya Pesta Dalok.

Rasionalisasi dari relasi antar manusia Uud Danum juga terwujud dalam Pesta D alok. Kurban yang dipersembahkan dalam pesta ini, selain sebagai wujud hormat kepada Tahala', juga merupakan wujud perdamaian antara warga masyarakat. Dalam doa-doa yang diucapkan 
oleh pemimpin Pesta Dalok, selalu terselip permohonan agar manusia yang didoakan dapat hidup baik dalam masyarakat. Kegiatan hopohau' yang dilaksanakan di akhir Pesta Dalok menunjukkan semangat kekeluargaan di dalam diri mereka. Sembari mengusir segala roh-roh jahat yang mungkin saja ada di sekitar mereka, hopohau' mempererat relasi mereka lewat gurauan.

Paul Ricoeur menggunakan mitos sebagai contoh dimana teka-teki tentang kejahatan coba dijawab, meski mitos itu sendiri melahirkan tekateki baru yang akan selalu dipecahkan oleh manusia sepanjang zaman agar mereka dapat memahami persoalan kejahatan dan kebaikan. Pesta D alok juga pada dasarnya sama. Sebagai sebuah si mbol agung dari puncak kehidupan dan kematian manusia, Pesta Dalok mencoba menjawab tekateki tentang kehidupan dan kematian itu sendiri. Jika dipandang dari satu sisi, teka-teki mengenai hidup dan mati manusia ini sepertinya sudah terjawab dalam rangkaian upacara tersebut.

Pesta Dalok ini sejatinya menggambarkan keseluruhan peziarahan manusia Dayak Uud Danum di dunia. Dalam tradisi ini, secara jelas bisa digambarkan ada peralihan dari semesta kehidupan manusia yang kacau (chaos) menuju dunia yang teratur (kosmos). Kisah Enuma Elish juga menunjukkan karakter yang sama, yaitu peralihan dari ketidakteraturan menuju keteraturan dunia. Situasi chaos dalam peziarahan manusia Uud Danum di dunia mengalami ketaraturan ketika arwah orang yang meninggal melewati ritus Pesta Dalok.

Arwah manusia yang sudah melewati Pesta Dalok juga pada dasarnya menjadi gambaran ideal manusia Uud Danum. Mereka berlomba-lomba mengejar kehidupan indah yang digambarkan dalam Betang Abadi. Di sana, manusia tidak lagi mengalami penderitaan dan kekacauan seperti yang mereka temui dalam kehidupan sehari-hari di dunia. Oleh karena itu, tatanan kehidupan masyarakat Uud Danum di dunia sehari-hari juga pada dasarnya mengacu pada kehidupan ideal di Betang Abadi.

Narasi yang disajikan lewat ritus Pesta Dalok menggambarkan keseluruhan perjuangan kehidupan manusia. Penggunaan tempayan, padi, Iovu, ayam, babi dan lain sebagainya dalam upacara ini benar-benar menunjukkan segala hal yang manusia alami di dunia. Ada kehidupan yang dilambangkan lewat padi dan rumah, ada kesejahteraan yang disimbolkan lewat babi dan lain sebagainya. Singkatnya, narasi ritual dalam Pesta $D$ alok merupakan momen keseluruhan peziarahan manusia Uud Danum.

Pada akhirnya, Pesta D al ok merupakan sebuah bahasa, sebuah si mbol yang coba ditafsirkan dari masa kemasa. Pesta ini menunjukkan kekuatan bahasa sebagai jalan manusia untuk menghubungkan dirinya dengan realitas yang kelihatan dan Realitas yang tak kelihatan. Paul Ricoeur 
menunjuk dengan tepat mitos sebagai bahasa primordial manusia yang digunakan untuk berkontak dengan Realitas yang tak terpahami.

\section{Penutup}

Paul Ricoeur menguraikan persoalan simbol-simbol dalamkehidupan manusia dengan sangat komprehensif dan lugas. Persoalan tersebut pertama-tama ia fokuskan pada perkara kejahatan sebagai persoalan fundamental manusia. Dalam refleksinya, Ricoeur menemukan "akar" permasalahan kejahatan dalam mitos-mitos penciptaan. Mitos-mitos klasik, salah satunya dalam Enuma Elish, mengkristalkan persoalan tersebut dalam narasi agungnya.

Pada ruang yang berbeda, namun memiliki dasar rasional yang sama, Pesta Dalok menjadi medan rasionalitas masyarakat Dayak Uud Danum dal am membahasakan relasi mereka dengan Tahala' dan sesamanya. Pesta ini menjadi sangat besar karena yang dirayakan adalah terbukanya gerbang bagi arwah yang meninggal menuju ke Betang Abadi. Pesta ini juga menjadi simbol yang sangat lugas untuk menunjukkan kompleksitas kehidupan masyarakat Dayak Uud Danum.

Kedua narasi besar ini, mitos dan Pesta D alok, menjadi pembelajaran yang sangat baik bagi manusia hari ini untuk menafsirkan kehidupannya sendiri. Banyak hal yang bisa dipelajari dari kedua hal tersebut, terlebih ketika kehidupan manusia modern ini coba dilihat secara jujur dan terbuka. Kehidupan modern yang terlalu menyederhanakan perkara tradisi hanya sebagai ritus yang membosankan akan kehilangan makna ritus itu sendiri.

Pelajaran lain yang tak kalah berharga adalah kegagalan manusia modern dalam menafsirkan realitas. Kesombongan dan kedangkalan berpikir dari manusia hari ini dalam menafsirkan realitas yang kompleks kemudian menjadikan kehidupan begitu kacau dan rusuh. Manusia menafsirkan peristiwa dan bahasa lepas dari beragam konteksnya sehingga dimaknai secara keliru. Pada akhirnya, konflik antar manusia pada hari ini juga menunjukkan kerdilnya cara berpikir manusia untuk memaknai persoalan.

Paul Ricoeur mengajarkan pentingnya sikap rendah hati, bersabar dan bijak dalam melihat kehidupan. Segala hal yang manusia alami hari ini, di masa lalu dan di masa depan merupakan simbol-simbol yang harus ditafsirkan secara utuh. Manusia perlu membaca realitas secara terusmenerus dan bijak agar semakin mendekati kebenaran tentang kehidupan itu sendiri.

* Trio Kurniawan

Pengajar Filsafat di STKIP Pamane Talino N gabang, Kalimantan Barat. Email: dominikustrio kurniawan@gmail.com 


\section{BIBLIOG RAFI}

Alloy, Surjani, dkk., M ozaik DayakKegeragaman Subsuku dan Bahasa Dayak di Kalimantan Barat, Pontianak: Institut Dayakologi, 2008.

Couderc, Pascal, 1988. "Preliminary N otes on the Ot Danum of the Melawi",Borneo Research Bulletin, Vol. 20, No. 1 (A pril 1988).

Dyson, L. dan Asharani, M., Tiwah U pacara Kematian Pada M asyarakat Dayak N gaju di Kalimantan Tengah, Jakarta: Departemen Pendidikan dan Kebudayan Direktorat Jenderal Kebudayaan, 1980.

N gawan, Sutimbang, Fonologi Bahasa Dayak U ud Danum [skripsi diterbitkan], Pontianak: Universitas Tanjungpura, 2013.

Raz, Joseph, "The Myth of Instrumental Rationality" dalam Journal of Ethics and Social Philosophy, Vol I, No. I, A pril 2005.

Ricoeur, Paul, The Symbolism of Evil, London: Beacon Press, 1967. 